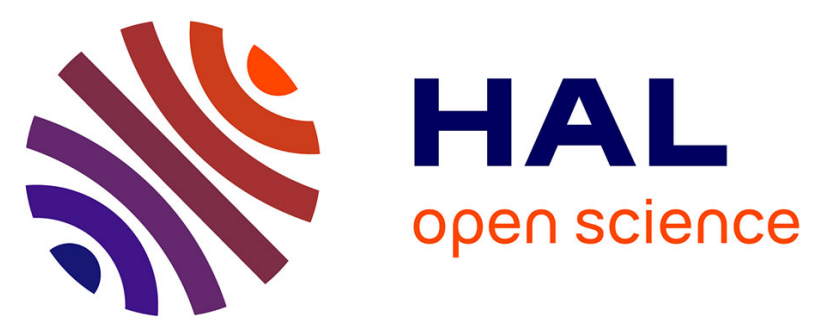

\title{
Day and night changes in energy expenditure of patients on automated peritoneal dialysis
}

\author{
Julien Aniort, Christophe Montaurier, Anais Poyet, Nathalie Meunier, \\ Aurélien Piraud, Didier Aguilera, Marc Bouiller, Ioana Enache, Youssef Ali, \\ Christelle Jouve, et al.
}

\section{To cite this version:}

Julien Aniort, Christophe Montaurier, Anais Poyet, Nathalie Meunier, Aurélien Piraud, et al.. Day and night changes in energy expenditure of patients on automated peritoneal dialysis. Clinical Nutrition, In press, 40 (5), pp.3454-3461. 10.1016/j.clnu.2020.11.028 . hal-03180109

\section{HAL Id: hal-03180109 \\ https://hal.inrae.fr/hal-03180109}

Submitted on 30 Jul 2021

HAL is a multi-disciplinary open access archive for the deposit and dissemination of scientific research documents, whether they are published or not. The documents may come from teaching and research institutions in France or abroad, or from public or private research centers.
L'archive ouverte pluridisciplinaire HAL, est destinée au dépôt et à la diffusion de documents scientifiques de niveau recherche, publiés ou non, émanant des établissements d'enseignement et de recherche français ou étrangers, des laboratoires publics ou privés.

\section{(c)(1)}

Distributed under a Creative Commons Attribution| 4.0 International License 


\title{
Day and night changes in energy expenditure of patients on automated peritoneal dialysis
}

\author{
Julien Aniort ${ }^{\mathrm{a}, \mathrm{b},{ }^{*}}$, Christophe Montaurier ${ }^{\mathrm{b}}$, Anais Poyet ${ }^{\mathrm{c}}$, Nathalie Meunier ${ }^{\mathrm{b}}$, \\ Aurélien Piraud ${ }^{\mathrm{a}}$, Didier Aguilera ${ }^{\mathrm{d}}$, Marc Bouiller ${ }^{\mathrm{e}}$, Ioana Enache ${ }^{\mathrm{f}}$, Youssef Ali ${ }^{\mathrm{g}}$, \\ Christelle Jouve $^{\mathrm{b}}$, Adeline Blot ${ }^{\mathrm{b}}$, Nicolas Farigon ${ }^{\mathrm{h}}$, Noël Cano ${ }^{\mathrm{b}, \mathrm{h}}$, Yves Boirie ${ }^{\mathrm{b}, \mathrm{h}}$, \\ Rudy Richard ${ }^{\mathrm{b}, \mathrm{i}}$, Anne Elisabeth Heng ${ }^{\mathrm{a}, \mathrm{b}}$
}

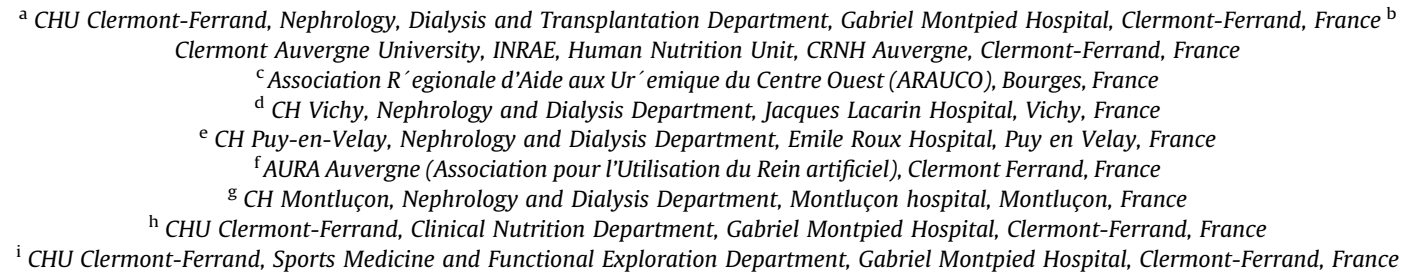

Rationale: Automated peritoneal dialysis (APD) treatment for end-stage kidney disease affords patients a degree of autonomy in everyday life. Clinical investigations of their energy expenditure (EE) are usually based on resting EE, which could mask day and night variations in EE. The aim of this study, therefore, was to compare the components of EE in APD patients and healthy control (C) subjects.

Material and method: Patients treated with APD for more than 3 months were compared with $\mathrm{C}$ volunteers matched for age and lean body mass (LBM). Biochemical analyses were performed and body composition was determined by DEXA to adjust EE to LBM. Total EE, its different components and respiratory quotients $(\mathrm{RQ})$ were measured by a gas exchange method in calorimetric chambers. Spontaneous total and activity-related EE (AEE) were also measured in free-living conditions over 4 days by a calibrated accelerometer and a heart rate monitor.

Results: APD $(\mathrm{n}=7)$ and $\mathrm{C}(\mathrm{n}=7)$ patients did not differ in age and body composition. REE did not differ between the two groups. However, prandial increase in EE adjusted for dietary energy intake was higher in APD patients $(+57.5 \pm 12.71 \mathrm{kcal} / \mathrm{h})$ than in C subjects $(+33.8 \pm 10.5 \mathrm{kcal} / \mathrm{h}, \mathrm{p}=0.003)$ and nocturnal decrease in EE tended to be lower in APD patients undergoing dialysis sessions $(-4.53 \pm 8.37 \mathrm{kcal} / \mathrm{h})$ than in subjects $(-11.8 \pm 7.69 \mathrm{kcal} / \mathrm{h}, \mathrm{p}=0.059)$. Resting RQ $(0.91 \pm 0.09$ vs $0.81 \pm 0.04, \mathrm{p}=0.032)$ and nocturnal $R Q(0.91 \pm 0.09$ vs $0.81 \pm 0.04, \mathrm{p}=0.032)$ were significantly higher in APD patients, indicating a preferential use of glucose substrate potentially absorbed across the peritoneum. AEE was lower in APD patients $(595.9 \pm 383.2 \mathrm{kcal} / \mathrm{d})$ than in C subjects $(1205.2 \pm 370.5 \mathrm{kcal} / \mathrm{d}, \mathrm{p}=0.011)$. In contrast, energy intakes were not significantly different $(1986 \pm 465$ vs $2083 \pm 377 \mathrm{kcal} / \mathrm{d}, \mathrm{p}=0.677)$.

Conclusion: Although the two groups had identical resting EE, APD patients had a higher prandial increase in EE, a lower activity-related EE and higher resting and nocturnal RQ than healthy subjects.

Abbreviations: APD, automated peritoneal dialysis; BW, body weight; C, control; EE, energy expenditure; DIT, diet-induced thermogenesis; FQ, food quotient; LBM, lean body mass; $\mathrm{RQ}$, respiratory quotient.

* Corresponding author. Department of Nephrology, CHU G. Montpied, 58 rue Montalembert, 63000, Clermont-Ferrand, France. Fax: +33 473752362.

E-mail address: janiort@chu-clermontferrand.fr (J. Aniort).

\section{Introduction}

Peritoneal dialysis is one of the alternatives to hemodialysis and kidney transplantation for the management of end-stage renal disease patients. Automated peritoneal dialysis (APD) is a variant in 
which the dialysate exchanges are carried out automatically by a cycler, usually at night. This makes it the technique of choice for autonomous patients wanting to have their day free. It is a specific metabolic situation in which substrate delivery and exchanges across the day can affect overall metabolic flexibility and modulate nutritional status. Indeed, despite having a high prevalence of protein-energy wasting [1] and a higher associated morbidity and mortality [2], APD patients are exposed to the risk of metabolic syndrome in relation to the development of an insulin-resistant state. The metabolic syndrome is present in about $50 \%$ of peritoneal dialysis patients [3]. It can preexist and/or be favored by peritoneal dialysis. Insulin resistance is related to the amount of perivisceral abdominal fat mass [4]. Peritoneal absorption of glucose from the dialysate causes an additional intake of energy which can promote the increase in fat mass and metabolic syndrome. This would particularly apply in the event of reduced physical activity and a fortiori if the dialysis sessions take place at night [5].

In order to efficiently match energy intake to energy requirements in APD patients, we need a better analysis of both the effect of peritoneal dialysis on daily energy expenditure (EE) and the nature of oxidized nutrients. Indirect calorimetry is able to estimate EE and the quality of substrate oxidation by measuring oxygen consumption and carbon dioxide production. It is noteworthy that most studies have only measured the resting EE of patients over a short period of time with a portable and easy-to-use canopy. They found no significant difference between peritoneal dialysis patients and healthy subjects [6,7] during short measurements which accounts for only a part of daily EE. Calorimetric chambers make it possible to study the impact of patient activities such as meals, physical exercise, rest, and sleep on EE across the day and night. Only one study has been carried out in peritoneal dialysis patients [8]. However, the authors measured only resting EE, which was greater than in non-dialysis chronic kidney disease patients. Of note, all these studies were conducted in patients treated with continuous ambulatory peritoneal dialysis and none included patients treated with APD. The doubly labeled water method is the benchmark technique for measuring total $\mathrm{EE}$ in free-living conditions. The technique was recently used to validate a questionnaire designed to estimate total $\mathrm{EE}$ in chronic kidney disease patients [9]. However, the method does not measure the daily variations in EE. Above all, doubly labeled water method require assumptions about hydration status that may well be invalidated in PD patients with fluid shifts.

The aim of the present study, therefore, was to explore energy metabolism, i.e. EE and respiratory quotient (RQ), as a function of activity (rest, walking, eating, sleep and nocturnal dialysis sessions) in patients treated with APD. Spontaneous activities were also determined in free-living conditions with a patient-calibrated accelerometer.

\section{Material and methods}

\subsection{Patient and study design}

The study was a cross-sectional study comparing end-stage renal disease patients receiving APD with a control group of healthy subjects (C). It was performed in the human nutrition unit (Centre de Recherche en Nutrition Humaine Auvergne) at the university hospital of Clermont-Ferrand, France. APD patients were male, aged 18-70 years, with end-stage renal disease who had been receiving APD for more than 3 months and who had a Baecke activity score [10] of 5-10. C patients were selected from a group of volunteers who had taken part in a previous study [11]. They were male, aged $18-70$ years, with a glomerular filtration rate of $>60 \mathrm{~mL} /$ $\min / 1.73 \mathrm{~m}^{2}$, as estimated by the CKD-EPI creatinine equation [12], and a Baecke activity score between 5 and 10. Non-inclusion criteria for the two groups were diabetes mellitus, thyroid disorder, catabolic disease (infection, cancer, congestive heart failure, surgery) in the previous 3 months and treatment with corticosteroids. For each included APD patient, a healthy individual was chosen with the closest age and lean body mass as measured by DEXA scan. The study protocol was approved by the Sud Est VI Research Ethics Committee (AU-1174) and registered at ClinicalTrials.gov (NCT03347305). All participants provided written informed consent.

\subsection{Medical consultation}

Each participant first underwent a consultation to identify cardiovascular risk factors: age $>55$ years, family history of early coronary artery disease, personal history of cardiovascular disease, current smoking or cessation of smoking for less than 3 years, treated or untreated hypertension, dyslipidemia and sedentary lifestyle. Patient treatments were also recorded. Daily physical activity was estimated with the Baecke questionnaire. Weight was measured to the nearest $0.1 \mathrm{~kg}$ on a SECA scale (SECA $\AA$, Les Mureaux France) and height to the nearest $0.2 \mathrm{~cm}$. Systolic and diastolic blood pressures were measured with a DINAMAP ProCare Monitor (General Electric Healthcare ${ }^{\circledR}$, France).

\subsection{Biological data}

Blood samples were taken in fasting conditions. Levels of hemoglobin, glucose, creatinine, urea, triglyceride, cholesterol and Creactive protein were measured by standard laboratory techniques with an auto-analyzer. Oral glucose load tests were performed in APD patients using orally administered $75 \mathrm{~g}$ of anhydrous pure glucose diluted in water. Blood samples were taken at 0, 30, 60, 120 and $180 \mathrm{~min}$ to determine glycemia and insulin levels. Insulin sensitivity was assessed with the HOMA-IR index [13] and the Matsuda score [14]. For assessing peritoneal permeability, the result of the last peritoneal equilibration test (PET) carried out in the center of the patients was collected. According Twardowski et al. [18] 2 L of a $2.3 \%$ glucose dialysate was infusate over $10 \mathrm{~min}$ for a $4 \mathrm{~h}$ dwell time. Patients were categorized based on the 4-h D/P creatinine and $\mathrm{D} / \mathrm{D}_{0}$ glucose ratios.

\subsection{Dietary questionnaire}

Four days before the start of the study, the patients were asked to fill in a detailed dietary record. The amounts of food were recorded either by weight or estimated using domestic measurements. The food record was double-checked with a dietitian using a validated food picture book to estimate the amounts consumed. Quantitative food data were converted into energy and nutrient intake with Nutrilog ${ }^{\circledR}$ software. Food quotient (FQ) was calculated according to the following formula:

\section{$F Q=\frac{0.207 \times \text { carbohydrate }(\%)+0.159 \times \text { fat }(\%)+0.193 \times \text { protein }(\%)}{0.207 \times \text { carbohydrate }(\%)+0.226 \times \text { fat }(\%)+0.243 \times \text { protein }(\%)}$}

\subsection{Energy expenditure study}

Quantitative and qualitative assessments of EE were made by indirect calorimetry. Briefly, gas exchanges were measured to determine EE using Weir's equation [15] and RQs, which indicate the nature of the preferentially oxidized substrates. Resting EE was 
first measured in the morning in fasted subjects, lying supine in thermoneutral conditions by indirect calorimetry over a period of $45 \mathrm{~min}$ after a $5 \mathrm{~min}$ rest. The subject breathed into a canopy connected to a Deltatrac II system (Datex-Engstrom Division, Instrumentarium Corp, Helsinki, Finland).

EE was then continuously evaluated by measuring gas exchanges with an indirect calorimetry method in two large opencircuit calorimetric chambers. Each chamber $\left(10 \mathrm{~m}^{2}, 32.5 \mathrm{~m}^{3}\right.$ total volume) was equipped with windows, bed, table, chair, TV and hi-fi sets, telephone, sink, toilet, and treadmill. An air lock prevented any gas perturbation during communication from outside the chamber when, for instance, meals were given to the volunteers. Both chambers were air-conditioned separately $\left(15-25 \pm 0.1{ }^{\circ} \mathrm{C}\right.$; $40-70 \pm 2 \%$ relative humidity) with the temperature set at $20-23{ }^{\circ} \mathrm{C}$ and relative humidity at $54-58 \%$, in accordance with each volunteer's preference. Air was continuously extracted at a controlled flow rate measured by a mass flow meter (Setaram, Caluire, France). The same flow of fresh air was pumped into the chambers. The flow was set at $1.2-6 \mathrm{~m}^{3} / \mathrm{h}$, according to the activities, gender and fat-free mass of each volunteer.

Inlet and outlet air flows were continuously analyzed with differential (dual-channel) analyzers for $\mathrm{O}_{2}$ (Oxymat 6, Siemens, Munich, Germany, scale 20-21\%) and $\mathrm{CO}_{2}$ (Ultramat 6, Siemens, scale $0-1 \%$ ). Gas analyzers were calibrated at the beginning and end of each measurement period with standard gas mixtures. Data were recorded every minute for $24 \mathrm{~h}$. Gas exchanges were computed taking into account gas analyzer drifts, gas volume variations in the chambers and the whole system response time ( $3 \mathrm{~min}$ ). In addition, signal noise was digitally filtered with a homedeveloped program using MATLAB (The MathWorks Inc., Natick, MA, USA). We checked the validity of gas exchange measurements, first by gravimetrically controlled simultaneous injection of $\mathrm{CO}_{2}$ and $\mathrm{N}_{2}$ [16], and second by combustion of ethanol. If the recovery rates were not $100 \%$, the results of the tests enabled us to correct respiratory volumes $\left(\mathrm{O}_{2}\right.$ and $\left.\mathrm{CO}_{2}\right)$ after the measurement period. Heart rate was recorded continuously by telemetry (Life Scope 6, Nihon Kohden, Tokyo, Japan). EE was calculated using the Weir equation with a correction factor of $1 \%$ for protein metabolism. $E E=3.9 \times V_{\mathrm{O}_{2}}(L)+1.1 \times V_{\mathrm{CO}_{2}}(L)[15]$.

Total EE and RQ were measured from 5 p.m. on day $1-5$ p.m. on day 2. Nocturnal EE and RQ were measured from 12 a.m. to 06 a.m. Sleeping EE and RQ were recorded in the calorimetric chambers during the least active period of the night. Resting EE and RQ were measured in the morning after the patients woke up, the latter remaining lying in their bed for a period of $1 \mathrm{~h}$ before taking breakfast and any physical activity. Walking EE and RQ were measured over two 30 -min walking sessions on a treadmill at $4 \mathrm{~km} /$ h. Prandial EE and respiratory quotient RQ were the mean values measured over 30 min during the three meals served in the calorimetric chamber (dinner at 7 p.m., breakfast at 8 a.m. and lunch at noon). Diet-induced thermogenesis (DIT) was evaluated by subtracting resting EE from postprandial EE measured over two hours following the start of dinner. Increases in prandial EE and DIT were adjusted for dietary energy intake by dividing them by dietary intake of the subject during the studied meal and mutiplying the results by a standard dietary intake (mean dietary intake during a meal in all subjects). The meals provided were the same for all participants. The overall energy intake of $2600 \mathrm{kcal} / 24 \mathrm{~h}$ corresponded to the average energy intake of adult males doing $1 \mathrm{~h}$ of walking at $4 \mathrm{~km} / \mathrm{h}$. The distribution was $50 \%$ carbohydrate, $35 \%$ fat and $15 \%$ protein $(\mathrm{FQ}=0.87)$. The ingredients used to prepare the meals were weighed and weighing of the uneaten food made it possible to determine the actual energy and nutrient intakes as calculated by the food composition tables of the Nutrilog ${ }^{\circledR}$ software.
Participants were fitted with a combined actigraph and heart rate monitor (ActiHeart ${ }^{\circledR}$ CamNtech, Cambridge, UK) in the calorimetric chamber and then for 4 days at home. The system was calibrated using measurements made in the calorimetric chambers. Heart rate data from the ActiHeart ${ }^{\circledR}$ monitor were used in combination with EE data from the calorimetric chambers to perform individual calibrations. Individual polynomial equations of the third order were established $\left(\mathrm{EE}(\mathrm{kJ} / \mathrm{min})=\mathrm{a}+\mathrm{b} \mathrm{HR}+\mathrm{c} \mathrm{HR}{ }^{2}+\mathrm{d}\right.$ $\left.\mathrm{HR}^{3}\right)$ ) [17]. These relationships were applied to assess total ambulatory EE from heart rates recorded with the ActiHeart ${ }^{\circledR}$ monitor in free-living conditions. Activity-related EE was calculated as the difference between total ambulatory EE and resting EE. The estimated physical activity level was calculated as the ratio of total ambulatory EE to resting EE.

\subsection{Peritoneal dialysis protocol}

APD patients performed a dialysis session with their cycler (Baxter ${ }^{\circledR}$ Home Choice Pro or Fresenius Medical Care ${ }^{\circledR}$ Sleepsafe Harmony) during the night spent in the calorimetric chambers. Dialysis protocols were standardized. Two APD programs were used depending on whether the patient was usually treated with standard or fluctuating APD. The standard protocol comprised four $2 \mathrm{~L}$ infusions of isotonic glucose solution (Physioneal ${ }^{\circledR} 1.36 \%$ or Bicavera ${ }^{\circledR} 1.5 \%$ ) with a dwell time of 90 min between 10 p.m. and 6 a.m. The fluctuating protocol comprised five $2 \mathrm{~L}$ infusions of isotonic glucose solution and a residual volume of $15 \%$ with a dwell time of $70 \mathrm{~min}$ between $10 \mathrm{p} . \mathrm{m}$. and $6 \mathrm{a} . \mathrm{m}$. At the end of the program, 2 L icodextrin (Extraneal $\left.{ }^{\circledR}\right)$ was infused in accordance with the patient's usual prescription. The ultrafiltration volume was recorded and samples of spent dialysate were taken to measure glucose concentration. Peritoneal glucose absorption was calculated according to the following formula:

$$
\begin{aligned}
\text { Absorbed glucose }= & V_{\text {dialysate }} \times C_{\text {glucose in dialysate }} \\
& -\left(V_{\text {dialysate }}-V_{\text {ultrafiltration }}\right) \\
& \times C_{\text {glucose in spent dialysate }}
\end{aligned}
$$

For assessing peritoneal permeability, the result of the last peritoneal equilibration test (PET) [18] carried out in the center of the patients was collected.

\subsection{Statistical analyses}

All statistical analyses were performed with $\mathrm{R}$ software (version 3.6.3) [19]. The sample size was calculated to be able to detect a $20 \%$ difference in total energy expenditure between the two groups with a $80 \%$ power and an $5 \% \alpha$ risk. The tests were twosided with a Type I error set at $\alpha=0.05$. Variables were presented as mean ( \pm standard-deviation) or median (interquartile range) according to statistical distribution (assumption of normality assessed by the Shapiro-Wilk test) for continuous data and as the number of patients and associated percentages for categorical parameters. Comparisons between the APD and $C$ groups were made with the $\chi 2$ test or Fisher exact test for categorical variables and with the Student t-test or the Mann-Whitney test for quantitative parameters (normality of distribution between pairs assessed by the Shapiro-Wilk test). Relations between continuous variables were analyzed by Pearson or Spearman correlation coefficient according to the statistical distribution and applying a Sidak's type I error correction to take into account multiple comparisons. 


\section{Results}

\subsection{Baseline characteristics}

In this study, 7 APD patients were enrolled and compared with $7 \mathrm{C}$ subjects. The characteristics of the study participants are shown in Table 1. APD patients had more dyslipidemia with higher triglyceride levels. They were more frequently hypertensive and were receiving more antihypertensive medications. Their hemoglobin level was also lower than that of the $C$ subjects. As expected, creatinine levels were significantly higher in APD patients. In contrast, the two groups did not differ in age, activity as assessed by the Baecke score, body weight (BW), height, body surface area, body mass index and the different parameters of body composition measured by DEXA scan. In the APD group, the parathyroid hormone level was $292.7 \pm 179.8 \mu \mathrm{g} / \mathrm{mL}$ and serum bicarbonate $23.8 \pm 2.5 \mathrm{mmol} / \mathrm{L}$. Peritoneal permeability according the last PET was high medium in 4 patients and low medium in 3 patients. The HOMA-IR index was $4.15 \pm 3.15$, and the Matsuda insulin sensitivity index $4.43 \pm 19$. A decrease in insulin sensitivity defined by the HOMA-IR index greater than 2.2 was observed in 5 patients. The HOMA-IR index and Matsuda insulin sensitivity index were significantly correlated with fat mass $(R=0.77$ and $R=-0.82$ respectively).

\subsection{Resting energy expenditure measurement}

Resting EE measured with the Deltatrac system was not different between APD patients $(1637 \pm 233 \mathrm{kcal} / 24 \mathrm{~h})$ and $\mathrm{C}$ subjects $(1667 \pm 246 \mathrm{kcal} / \mathrm{d}, \mathrm{p}=0.824)$. Results were the same after adjustment for lean body mass $(27.0 \pm 4.5 \mathrm{vs} 26.9 \pm 2.9 \mathrm{kcal} / \mathrm{kg}$ LBM/d, p > 0.9) or body weight ( $21.4 \pm 4.5 \mathrm{vs} 21.9 \pm 2.8 \mathrm{kcal} / \mathrm{kg} \mathrm{BW} /$ $24 \mathrm{~h}, \mathrm{p}=0.824)$. During this measurement, RQ did not differ: $0.83 \pm 0.05$ vs $0.86 \pm 0.06, p=0.386$ for the APD and C groups, respectively.

\subsection{Calorimetric chamber study}

\subsubsection{Dietary energy intake and glucose absorption during} peritoneal dialysis

During the three meals given in the calorimetric chambers, APD patients consumed $2056 \pm 436 \mathrm{kcal} / \mathrm{d}$ and $\mathrm{C}$ subjects $2300 \pm 140 \mathrm{kcal} / \mathrm{d}(\mathrm{p}=0.184)$ i.e. $26.5 \pm 5 \mathrm{kcal} / \mathrm{kg} \mathrm{BW} / \mathrm{d}$ for APD patients and $30.3 \pm 3.5 \mathrm{kcal} / \mathrm{kg} \mathrm{BW} / \mathrm{d}$ for $\mathrm{C}$ subjects $(\mathrm{p}=0.125)$. APD patients consumed slightly less carbohydrate $(50.5 \pm 2.3$ vs $55.7 \pm 1.5 \%, \mathrm{p}<0.001)$ and a little more protein $(14.7 \pm 1.0$ vs $11.1 \pm 3.6 \%, p=0.027)$ compared to $C$ subjects. The proportion of consumed lipid was not different $(32.2 \pm 2.4$ vs $31.8 \pm 1.7 \%$, $\mathrm{p}=0.735$ ) between the two groups: FQ was $0.86 \pm 0.01$ for APD patients and $0.87 \pm 0.01$ for $C$ subjects $(\mathrm{p}=0.027)$. In APD patients, peritoneal glucose absorption was $55.01 \pm 7.7 \mathrm{~g}$, i.e. $220 \pm 31 \mathrm{kcal}$ or $3.0 \pm 1.0 \mathrm{kcal} / \mathrm{kg} \mathrm{BW}$.

\subsubsection{Energy expenditure in controlled conditions}

Values of total EE and its components are shown in Table 2. Total EE was not different between APD patients and C subjects. No significant difference was found in resting, sleeping, nocturnal walking and prandial EE between APD patients and C subjects. However, an upward trend was observed for nocturnal and prandial EE in APD patients. Pearson correlation coefficients between total $\mathrm{EE}$ and its components and between subjects' age and anthropometric data are given in Table 3. Body weight, body mass index, body surface area, lean body mass and fat mass were significantly positively correlated with total, resting, sleeping, walking and prandial EE. Variations in EE relative to resting EE at nighttime and during meals are shown in Fig. 1. Decrease in EE during the night tended to be lower in APD patients undergoing dialysis sessions $(-4.53 \pm 8.37 \mathrm{kcal} / \mathrm{h})$ than in $\mathrm{C}$ subjects ($11.8 \pm 7.69 \mathrm{kcal} / \mathrm{h}, \mathrm{p}=0.058)$. Prandial increase in EE adjusted for dietary energy intake was higher in APD patients $(+57.5 \pm 12.71 \mathrm{kcal} / \mathrm{h})$ than in $\mathrm{C}$ subjects $(+33.8 \pm 10.5 \mathrm{kcal} / \mathrm{h}$, $\mathrm{p}=0.003)$. The difference was significant for breakfast

Table 1

Characteristics of the participants.

\begin{tabular}{|c|c|c|c|}
\hline & C subjects $(n=7)$ & APD patients $(\mathrm{n}=7)$ & $\mathrm{p}$ \\
\hline Age (years) & $52.7 \pm 5.5$ & $50.4 \pm 15.8$ & 0.724 \\
\hline Male $\mathrm{n}$ & 7 & 7 & $>0.9$ \\
\hline Weight (kg) & $77.1 \pm 13.7$ & $80.4 \pm 24.1$ & 0.755 \\
\hline Height $(\mathrm{cm})$ & 174.4 & 173.9 & 0.882 \\
\hline BMI $\left(\mathrm{kg} \cdot \mathrm{m}^{-2}\right)$ & 25.3 & 26.5 & 0.713 \\
\hline $\operatorname{BSA}\left(\mathrm{m}^{2}\right)$ & $1.93 \pm 0.18$ & $1.95 \pm 0.31$ & 0.847 \\
\hline Tobacco smoking n (\%) & $0(0)$ & $2(29)$ & 0.171 \\
\hline Baecke Activity Score & $8.46 \pm 1.42$ & $8.22 \pm 1.30$ & 0.744 \\
\hline Dyslipemia n (\%) & $0(0)$ & $4(57)$ & 0.015 \\
\hline Hypertension n (\%) & $0(0)$ & $5(71)$ & 0.002 \\
\hline Antihypertensive medication $\mathrm{n}(\%)$ & $0(0)$ & $5(71)$ & 0.002 \\
\hline Betablocker n (\%) & $0(0)$ & $2(29)$ & 0.147 \\
\hline Hemoglobin (g/dL) & $15.0 \pm 1.1$ & $11.7 \pm 0.8$ & $<0.0001$ \\
\hline Glucose (mmol. $\left.\mathrm{L}^{-1}\right)$ & $5.2 \pm 0.4$ & $5.2 \pm 0.9$ & $>0.9$ \\
\hline Total cholesterol (mmol. $\left.\mathrm{L}^{-1}\right)$ & $5.04 \pm 0.52$ & $4.32 \pm 1.34$ & 0.211 \\
\hline Triglycerides $\left(\mathrm{mmol}^{-1} \mathrm{~L}^{-1}\right)$ & $0.66 \pm 0.26$ & $2.67 \pm 1.11$ & $<0.001$ \\
\hline HDLc $\left(m m o l . L^{-1}\right)$ & $1.53 \pm 0.26$ & $1.15 \pm 0.54$ & 0.121 \\
\hline $\operatorname{LDLc}\left(\mathrm{mmol} . \mathrm{L}^{-1}\right)$ & $3.12 \pm 0.48$ & $2.07 \pm 0.90$ & 0.018 \\
\hline Urea $\left(\mathrm{mmol}^{-\mathrm{L}^{-1}}\right)$ & $4.9 \pm 0.2$ & $18.2 \pm 4.5$ & $<0.0001$ \\
\hline Creatinine $\left(\mu \mathrm{mol} . \mathrm{L}^{-1}\right)$ & $82.7 \pm 10.0$ & $1095.7 \pm 405.2$ & $<0.0001$ \\
\hline $\mathrm{CRP}(\mathrm{mg} / \mathrm{dL})$ & $<2.9$ & $<2.9$ & $>0.9$ \\
\hline Lean body mass ( $\mathrm{kg}$ ) & $62.2 \pm 9.4$ & $62.3 \pm 14.0$ & $>0.9$ \\
\hline Muscle mass (kg) & $59.6 \pm 8.9$ & $60.0 \pm 13.6$ & $>0.9$ \\
\hline Appendicular muscle mass (kg) & $26.2 \pm 4.0$ & $24.3 \pm 5.2$ & 0.466 \\
\hline Fat mass $(\mathrm{kg})$ & $14.8 \pm 4.8$ & $18.0 \pm 10.9$ & 0.492 \\
\hline Fat mass (\% total) & $18.9 \pm 2.8$ & $20.9 \pm 7.3$ & 0.530 \\
\hline Bone mineral content (kg) & $26.4 \pm 5.6$ & $23.8 \pm 5.6$ & 0.393 \\
\hline
\end{tabular}

APD, Automated peritoneal dialysis; BMI, body mass index; BSA, body surface area; C, control; CRP, C-reactive protein. 
Table 2

Energy expenditure in calorimetric chambers.

\begin{tabular}{|c|c|c|c|}
\hline & C subjects $(n=7)$ & APD patients $(n=7)$ & $\mathrm{p}$ \\
\hline \multicolumn{4}{|l|}{ Total EE } \\
\hline $\mathrm{kcal} / \mathrm{d}$ & $2315 \pm 353$ & $2176 \pm 331$ & 0.462 \\
\hline $\mathrm{kcal} / \mathrm{kg}$ LBM/d & $37.9 \pm 5.4$ & $35.0 \pm 2.6$ & 0.223 \\
\hline \multicolumn{4}{|l|}{ Resting EE } \\
\hline $\mathrm{kcal} / \mathrm{d}$ & $73.5 \pm 13.7$ & $71.7 \pm 11.8$ & 0.798 \\
\hline $\mathrm{kcal} / \mathrm{kg}$ LBM/h & $1.21 \pm 0.23$ & $1.16 \pm 0.13$ & 0.631 \\
\hline \multicolumn{4}{|l|}{ Sleeping EE } \\
\hline $\mathrm{kcal} / \mathrm{d}$ & $65.04 \pm 10.2$ & $57.7 \pm 10.3$ & 0.203 \\
\hline $\mathrm{kcal} / \mathrm{kg} \mathrm{LBM} / \mathrm{h}$ & $1.07 \pm 0.17$ & $0.93 \pm 0.14$ & 0.129 \\
\hline \multicolumn{4}{|l|}{ Nighttime EE } \\
\hline $\mathrm{kcal} / \mathrm{d}$ & $69.0 \pm 12.7$ & $59.9 \pm 9.92$ & 0.161 \\
\hline $\mathrm{kcal} / \mathrm{kg} \mathrm{LBM} / \mathrm{h}$ & $1.13 \pm 0.20$ & $0.97 \pm 0.14$ & 0.096 \\
\hline \multicolumn{4}{|l|}{ Walking EE } \\
\hline $\mathrm{kcal} / \mathrm{d}$ & $290.4 \pm 50.4$ & $264.2 \pm 49.3$ & 0.887 \\
\hline $\mathrm{kcal} / \mathrm{kg} \mathrm{LBM} / \mathrm{h}$ & $4.07 \pm 0.40$ & $4.23 \pm 0.26$ & 0.453 \\
\hline \multicolumn{4}{|l|}{ Prandial EE } \\
\hline $\mathrm{kcal} / \mathrm{d}$ & $128.6 \pm 29.0$ & $107.5 \pm 14.0$ & 0.083 \\
\hline $\mathrm{kcal} / \mathrm{kg}$ LBM/h & $2.10 \pm 0.43$ & $1.74 \pm 0.172$ & 0.063 \\
\hline \multicolumn{4}{|l|}{ Breakfast EE } \\
\hline $\mathrm{kcal} / \mathrm{d}$ & $124.9 \pm 26.4$ & $100.2 \pm 15.8$ & 0.055 \\
\hline $\mathrm{kcal} / \mathrm{kg} \mathrm{LBM} / \mathrm{h}$ & $2.02 \pm 0.28$ & $1.63 \pm 0.28$ & 0.021 \\
\hline \multicolumn{4}{|l|}{ Lunch EE } \\
\hline $\mathrm{kcal} / \mathrm{d}$ & $122.4 \pm 31.2$ & $108.2 \pm 19.6$ & 0.326 \\
\hline $\mathrm{kcal} / \mathrm{kg} \mathrm{LBM} / \mathrm{h}$ & $2.01 \pm 0.56$ & $1.74 \pm 0.23$ & 0.260 \\
\hline \multicolumn{4}{|l|}{ Dinner EE } \\
\hline $\mathrm{kcal} / \mathrm{d}$ & $138.8 \pm 36.0$ & $114.1 \pm 14.2$ & 0.117 \\
\hline $\mathrm{kcal} / \mathrm{kg}$ LBM/h & $2.26 \pm 0.52$ & $1.84 \pm 0.16$ & 0.065 \\
\hline
\end{tabular}

APD, Automated peritoneal dialysis; C, control; EE, energy expenditure.

Table 3

Pearson correlation coefficients between total energy expenditure and its components with subjects characteristics.

\begin{tabular}{lllllll}
\hline & TEE & REE & SEE & NEE & WEE & PEE \\
\hline Age & 0.27 & 0.35 & -0.07 & -0.10 & 0.50 & 0.38 \\
Weight & $0.78^{*}$ & $0.73^{*}$ & $0.63^{*}$ & $0.59^{*}$ & $0.90^{*}$ & $0.64^{*}$ \\
Height & 0.33 & 0.02 & 0.36 & 0.31 & 0.32 & 0.11 \\
BMI & $0.72^{*}$ & $0.76^{*}$ & $0.54^{*}$ & 0.52 & $0.83^{*}$ & $0.63^{*}$ \\
BSA & $0.77^{*}$ & $0.69^{*}$ & $0.59^{*}$ & $0.54^{*}$ & $0.91^{*}$ & $0.61^{*}$ \\
LBM & $0.78^{*}$ & $0.68^{*}$ & $0.57^{*}$ & 0.52 & $0.93^{*}$ & $0.59^{*}$ \\
MM & $0.78^{*}$ & $0.68^{*}$ & $0.57^{*}$ & 0.52 & $0.93^{*}$ & $0.59^{*}$ \\
FM & $0.71^{*}$ & $0.73^{*}$ & $0.65^{*}$ & $0.63^{*}$ & $0.75^{*}$ & $0.66^{*}$ \\
BMC & $0.59^{*}$ & 0.48 & 0.41 & 0.34 & $0.78^{*}$ & $0.30^{*}$ \\
\hline
\end{tabular}

ATM, adipose tissue mass; BMC, bone mineral content; BMI, body mass index; BSA, body surface area; FM, fat mass; LBM, lean body mass; MM, muscle mass; TEE, total energy expenditure; REE, resting energy expenditure; SEE, sleep energy expenditure; NEE, nighttime energy expenditure; WEE, walking energy expenditure; PEE, prandial energy expenditure $* \mathrm{p}<0.05$.

$(+72.4 \pm 16.5 \mathrm{kcal} / \mathrm{h}$ vs $36.3 \pm 19.8 \mathrm{kcal} / \mathrm{h}, \mathrm{p}=0.003)$ and dinner $(+64.8 .0 \pm 21.1$ vs $38.2 \pm 13.9 \mathrm{kcal} / \mathrm{h}, \mathrm{p}=0.017)$. Variations in $\mathrm{EE}$ relative to REE during the night and meals were not related to anthropometric data. DIT over two hours after dinner and adjusted for energy intake was $43.2 \pm 14.8$ in APD patients and $26.3 \pm 13.3 \mathrm{kcal} / \mathrm{h}$ in $\mathrm{C}$ subjects $(\mathrm{p}=0.045)$.

$\mathrm{RQ}$ values measured during the time spent in the calorimetric chamber are given in Table 4. The average 24-h RQ was not different between the two groups. Conversely, resting, nocturnal and dinner RQs were higher in APD patients than in C subjects.

\subsection{Study in free-living conditions}

\subsubsection{Food intake}

Dietary energy intakes were calculated to be $1987 \pm 469 \mathrm{kcal} /$ $\mathrm{d}$ in APD patients and $2083 \pm 378 \mathrm{kcal} / \mathrm{d}$ in C subjects $(\mathrm{p}=0.677)$, i.e. $26.6 \pm 9.9 \mathrm{kcal} / \mathrm{kg} \mathrm{BW} / \mathrm{d}$ in APD patients and $28 \pm 7 \mathrm{kcal} / \mathrm{kg} \mathrm{BW} /$ $\mathrm{d}$ in $\mathrm{C}$ subjects $(\mathrm{p}=0.812$ ). The proportions of carbohydrates
$(42.5 \pm 6.4$ vs $45.5 \pm 7.4 \%, \mathrm{p}=0.443)$, proteins $(18.7 \pm 1.9$ vs $18.4 \pm 1.8 \%, \mathrm{p}>0.9$ ) and lipids ( $35.7 \pm 5.6$ vs $35.8 \pm 6.7 \%, \mathrm{p}>0.9$ ) were not different between APD patients and $C$ subjects. FQ was $0.84 \pm 0.02$ for APD patients and $0.85 \pm 0.02$ for $C$ subjects $(\mathrm{p}=0.608)$.

\subsubsection{Energy expenditure in free-living conditions}

Estimations of total ambulatory EE from measurements made in free-living conditions are shown in Fig. 2. Total ambulatory EE was estimated to be $2234 \pm 470 \mathrm{kcal} / \mathrm{d}$ in APD patients against $2872 \pm 395 \mathrm{kcal} / \mathrm{d}$ in $\mathrm{C}$ subjects $(\mathrm{p}=0.018)$ i.e. $29.2 \pm 6.9 \mathrm{kcal} / \mathrm{kg}$ $\mathrm{BW} / \mathrm{d}$ and $38.1 \pm 7.2 \mathrm{kcal} / \mathrm{kg} \mathrm{BW} / \mathrm{d}(\mathrm{p}=0.036)$, respectively. After adjustment for lean body mass, total EE was $36.7 \pm 7 \mathrm{kcal} / \mathrm{kg} \mathrm{LBM} /$ $\mathrm{d}$ in APD patients and $46.9 \pm 8.5 \mathrm{kcal} / \mathrm{kg} \mathrm{LBM} / \mathrm{d}$ in $\mathrm{C}$ subjects $(\mathrm{p}=0.033)$. Variations in total EE between free-living conditions and those of the calorimetric chambers was $+48.7[+19.0-+50.4]$ $\%$ for $\mathrm{C}$ patients and $-5.5[-11.1-+8.2] \%$ for APD patients $(\mathrm{p}<0.001)$. Activity-related EE was significantly lower in APD patients $(467 \pm 465 \mathrm{kcal} / \mathrm{d})$ than in healthy subjects $(1151 \pm 443 \mathrm{kcal} /$ $\mathrm{d}, \mathrm{p}=0.016)$. The results were the same after adjustment for lean body mass ( $7.80 \pm 7.1 \mathrm{vs} 19.2 \pm 7.4 \mathrm{kcal} / \mathrm{kg} \mathrm{LBM} / \mathrm{d}, \mathrm{p}=0.013)$. The estimated physical activity level was $1.29 \pm 0.31$ in APD patients and $1.69 \pm 0.27$ in $C$ subjects $(\mathrm{p}=0.024)$.

\section{Discussion}

This study investigated EE for the first time in APD patients undergoing dialysis treatment in a calorimetric chamber. Results showed that resting EE was not different between APD patients and $C$ subjects. However, APD patients had a greater prandial increase in $\mathrm{EE}$, lower activity-related $\mathrm{EE}$ than $\mathrm{C}$ subjects and higher resting and nocturnal RQ than healthy subjects.

Most studies performed in chronic kidney disease patients have focused on resting EE. In non-dialysis patients, resting EE was reported to be lower than that of healthy controls, including after adjustment for lean body mass [20,21]. In a previous study, we found that in kidney transplant patients resting EE was not different from that of healthy volunteers [11]. In peritoneal dialysis patients, resting EE was found to be similar [6,7] to that of healthy subjects. In studies of hemodialysis patients, resting EE was similar [22] or higher [23-25]. These apparently discordant results can be explained by differences in the characteristics of the patients enrolled and in adjustment for cofactors that influence EE. The results are comparable to those found in our study, in which resting EE measured with a canopy or in a calorimeter chamber was not different between APD patients and C subjects.

It is classically recognized that chronic kidney disease patients and in particular those treated by dialysis have lower activityrelated EE than healthy sedentary subjects [26]. In our study, APD patients clearly had less activity-related EE than $C$ subjects despite the absence of any significant difference between the two groups in age, muscle mass, CRP level and results of the Baecke activity questionnaire. It is acknowledged that purification of uremic toxins by hemodialysis or peritoneal dialysis is not perfect. In addition to the anemia caused by kidney failure, the accumulation of uremic toxins can cause a feeling of tiredness and ill-being in patients, thereby reducing their activities [27]. After kidney transplantation, the elimination of toxins is more efficient and as a result the physical capacity of patients is improved [28]. The deleterious action of uremic toxins can be explained by the release of proinflammatory cytokines, which results in a low-grade chronic inflammatory state [29], and the appearance of muscle mitochondrial dysfunction [30]. Of note, total ambulatory EE in our study was fairly close to that of clinical guidelines (30-35 kcal $/ \mathrm{kg} \mathrm{BW} / \mathrm{d}$ ) [31]. However, physical activity-related EE was fairly variable and should 
A

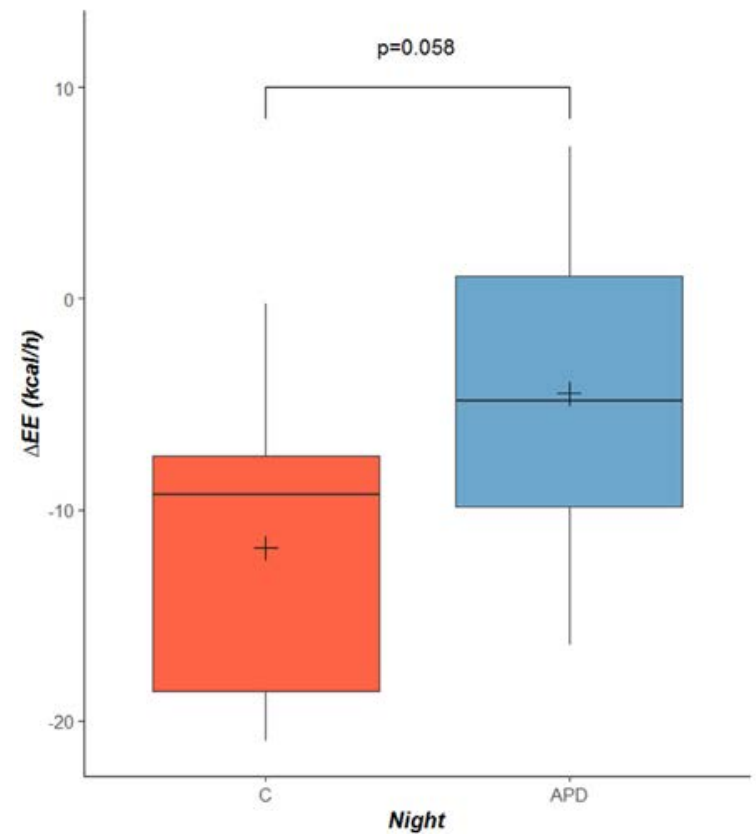

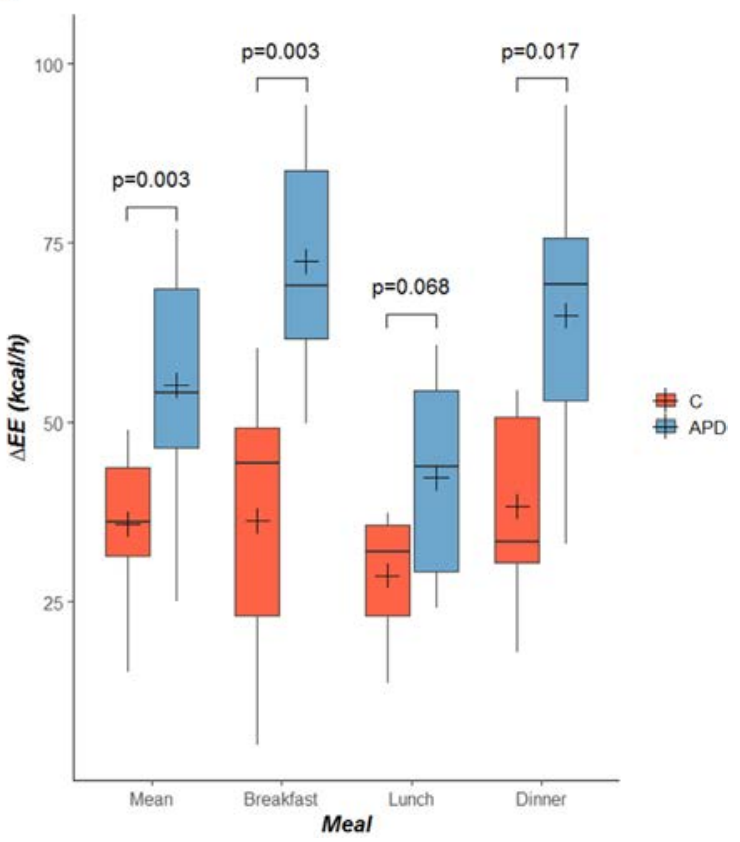

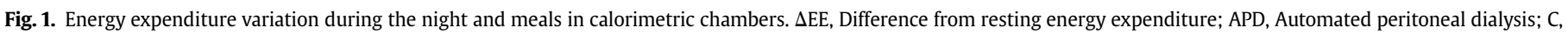
control. P-value obtained with Student T test.

Table 4

Respiratory quotients in calorimetric chambers.

\begin{tabular}{llll}
\hline & C subjects $(\mathrm{n}=7)$ & APD patients $(\mathrm{n}=7)$ & $\mathrm{p}$ \\
\hline 24-h RQ & $0.83 \pm 0.02$ & $0.86 \pm 0.04$ & 0.064 \\
Resting RQ & $0.81 \pm 0.04$ & $0.91 \pm 0.09$ & 0.032 \\
Sleeping RQ & $0.83 \pm 0.04$ & $0.88 \pm 0.09$ & 0.164 \\
Nighttime RQ & $0.83 \pm 0.03$ & $0.90 \pm 0.09$ & 0.032 \\
Walking RQ & $0.84 \pm 0.03$ & $0.84 \pm 0.08$ & $>0.9$ \\
Prandial RQ & $0.77 \pm 0.02$ & $0.80 \pm 0.03$ & 0.036 \\
Breakfast RQ & $0.74 \pm 0.06$ & $0.77 \pm 0.03$ & 0.183 \\
Lunch QR & $0.78 \pm 0.02$ & $0.82 \pm 0.07$ & 0.141 \\
Dinner QR & $0.75 \pm 0.03$ & $0.87 \pm 0.06$ & 0.007 \\
\hline
\end{tabular}

APD, Automated peritoneal dialysis; C, control; RQ, respiratory quotient.

be included in the regular assessment to better adapt intake to the needs of patients.

Surprisingly, the increase in EE during meals was higher in APD patients. We hypothesized that this was due to an increase in early DIT, which is the increase in EE during the $4-5 \mathrm{~h}$ following the ingestion of a meal. DIT corresponds to a small proportion of total EE (between 5 and 15\%). It comprises energy expended in the digestion, transport and storage of nutrients and heat dissipated by brown adipose tissue. To overcome variations in EE related to physical activity and energy intake, we studied the $2 \mathrm{~h}$ following the evening meal, which corresponds to the period of least physical activity, and adjusted the result for estimated dietary intake. Our results suggested an increase in DIT in DPA patients.

Patients undergoing peritoneal dialysis sessions overnight tended to have a decrease in nocturnal EE compared to healthy subjects. EE has already been measured during a hemodialysis session. Carrying out this treatment seems to cause an increase in basal metabolism [24]. It is probably the result of the energy expended during the transfer of solute between the organism compartments and the activation of the cardiovascular compensation mechanisms in response to the hypovolemia induced by ultrafiltration. During peritoneal dialysis, the cardiovascular system is less stimulated. On the other hand, part of the increase in EE could be caused by transperitoneal absorption of glucose. Absorbed glucose is partly used as an energy substrate, as evidenced by the increase in the RQ of APD patients in our study. Increased EE could be caused by DIT and glucose storage with activation of lipogenesis. Accordingly, a relation was recently established between glucose absorption and fat mass in peritoneal dialysis patients [32].

One of the most interesting results of this study is the increase in the resting and night RQ in patients with APD. To our knowledge, there is no study of hepatic glucose uptake administered by transperitoneal route. Glucose absorbed by visceral peritoneum could stimulate its hepatic uptake increasing glucose portal signal [33]. During overnight fast, skeletal muscle then hepatic glycogen stocks are initially used to produce glucose. When glycogen stock are decreased lipolysis provides glycerol for gluconeogenesis and free fatty acids as energetic substrates [34]. The continuous nightly supply of glucose via transperitoneal route could oppose this metabolic switch, promote fat tissue accumulation and metabolic syndrome [35]. Glucose load increases with dialysate volume, dwell time, dialysate glucose concentration and peritoneal permeability. To date, no significant relationship has been shown between insulin resistance levels, peritoneal permeability and glucose uptake measured during a PET [36]. However, patients with the same peritoneal permeability may not have the same glucose load depending on the usual dialysis prescription and dialysis vintage. In clinical practice, our results should encourage reducing glucose concentration in dialysate and carbohydrate consumption especially at breakfast in APD patients.

This study has several limitations. First, to circumvent the effects related to variations in female hormones during the menstrual cycle only males were enrolled. Our results are therefore not transferable to women. Second, the study sample size was small. However, the complexity of the protocol would have made a larger study difficult. The small number of participants did not allow for multivariate analysis, which would need to be performed to establish the respective roles of the determinants of EE. Finally, indirect calorimetry provides a measure of overall EE expenditure 
A

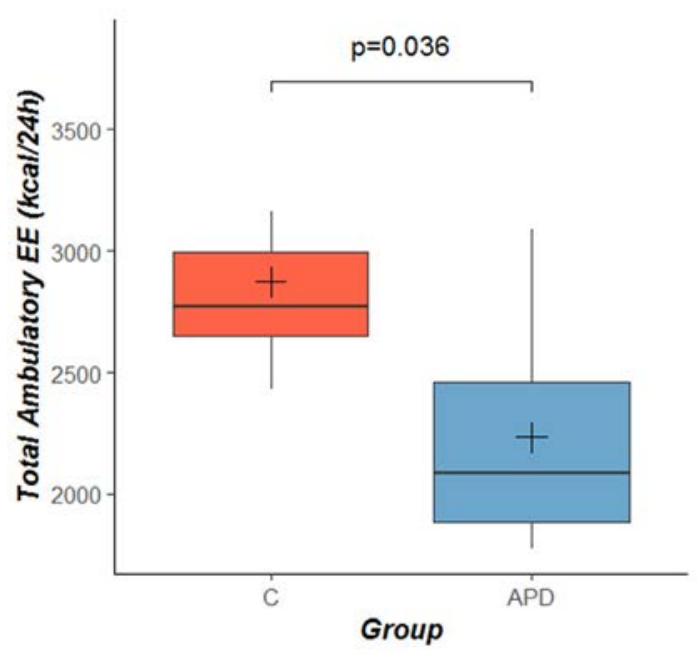

C

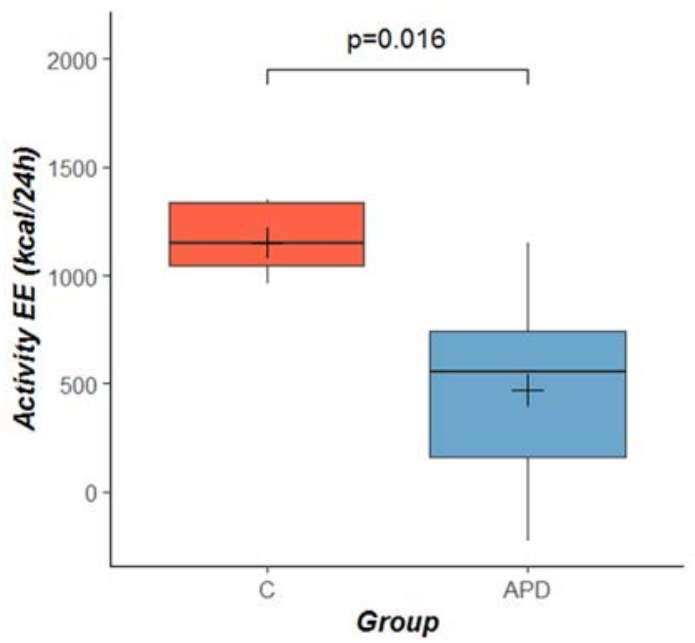

B

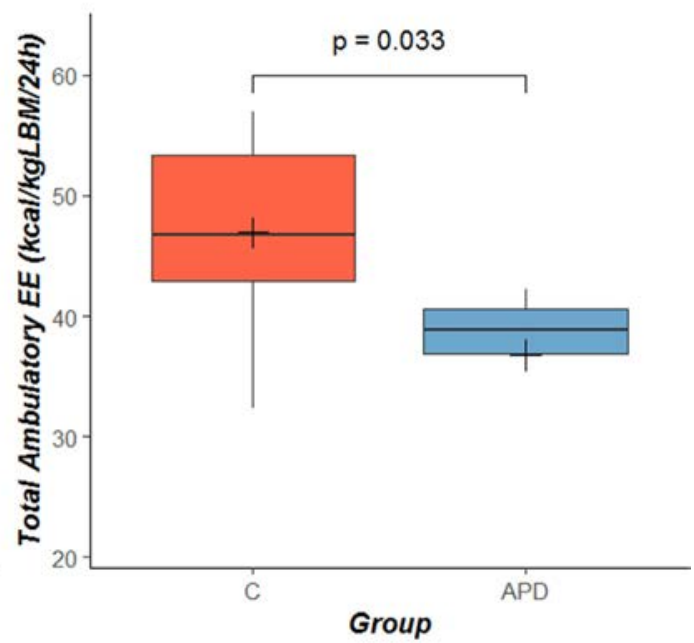

D

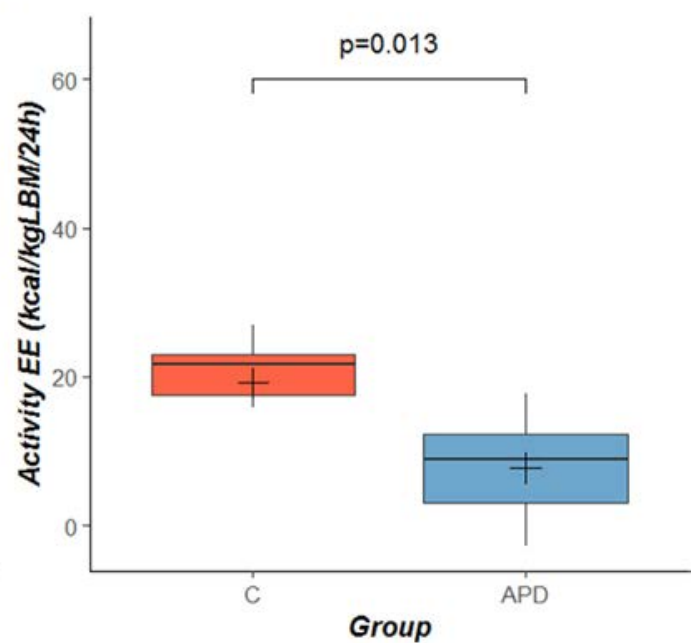

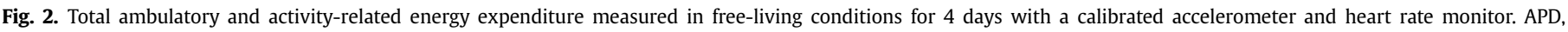
Automated peritoneal dialysis; C, control. P-value obtained with Student T test.

but does not allow to mesure separately part related with nutrient metabolism and heat dissipated in the environment. Direct calorimetry would be difficult to perform in patients undergoing dialysis with a cycler producing heat. Recent developments in infrared thermography could be used in the future to specify the components of postprandial EE in APD patients.

In conclusion, although our findings showed that resting EE did not differ between APD patients and C subjects, a complete study of the different components of EE in calorimetric chambers identified several differences in other conditions. In APD patients, meals were associated with a greater increase in EE, activity-related EE was reduced, resting and nighttime RQ were increased. These findings have practical implications such as limiting carbohydrate intake in the diet and glucose dialysate content, and encouraging patients to have regular physical activity. We suggest that there are several possible relations between our results and the metabolic disorders induced by uremic toxins and/or dialysis.

\section{Funding}

This study was funded by grants from the SFNCM (Prix Nestlé Health Science 2014) and from the clinical research department of the Clermont-Ferrand University hospital AOI 2014 ANIORT.

\section{Author contribution statements}

Julien Aniort: Conceptualization, Formal analysis, Funding acquisition, Writing - Original Draft; Christophe Montaurier: Data curation, Formal analysis, Investigation, Software, Writing - Original Draft; Anais Poyet: Investigation Nathalie Meunier: Data curation Aurélien Piraud: Investigation Didier Aguilera: Investigation Marc Bouiller: Investigation Ioana Enache: Investigation Youssef Ali: Investigation, Christelle Jouve: Investigation; Adeline Blot: Investigation Nicolas Farigon: Investigation Noël Cano: Supervision, Writing Reviewing and Editing Yves Boirie Supervision, Writing Reviewing and Editing Rudy Richard: Supervision, Writing Reviewing and Editing Anne Elisabeth Heng: Conceptualization, Supervision, Writing Reviewing and Editing.

\section{Conflict of interest}

The authors declare that they have no conflict of interest.

\section{Acknowledgements}

We are indebted to Mr. Jeffrey Watts for assistance in the preparation of the manuscript. 


\section{References}

[1] Cianciaruso B, Brunori G, Kopple JD, Traverso G, Panarello G, Enia G, et al. Cross-sectional comparison of malnutrition in continuous ambulatory peritoneal dialysis and hemodialysis patients. Am J Kidney Dis Offic J Natl Kidney Found 1995;26(3):475-86.

[2] Leinig CE, Moraes T, Ribeiro S, Riella MC, Olandoski M, Martins C, et al. Predictive value of malnutrition markers for mortality in peritoneal dialysis patients. J Ren Nutr 2011;21(2):176-83.

[3] Park SH, Lindholm B. Definition of metabolic syndrome in peritoneal dialysis. Perit Dial Int 2009:29(Suppl 2):S137-44.

[4] Ross R, Aru J, Freeman J, Hudson R, Janssen I. Abdominal adiposity and insulin resistance in obese men. Am J Physiol Endocrinol Metab 2002;282(3): E657-63.

[5] de Moraes TP, Andreoli MC, Canziani ME, da Silva DR, Caramori JC, Ponce D, et al. Icodextrin reduces insulin resistance in non-diabetic patients undergoing automated peritoneal dialysis: results of a randomized controlled trial (STARCH). Nephrol Dial Transplant 2015;30(11):1905-11.

[6] Harty J, Conway L, Keegan M, Curwell J, Venning M, Campbell I, et al. Energy metabolism during CAPD: a controlled study. Adv Perit Dial 1995;11:229-33.

[7] Bazanelli AP, Kamimura MA da Silva CB, Avesani CM, Lopes MG, Manfredi SR, et al. Resting energy expenditure in peritoneal dialysis patients. Perit Dial Int 2006;26(6):697-704.

[8] Neyra R, Chen KY, Sun M, Shyr Y, Hakim RM, Ikizler TA. Increased resting energy expenditure in patients with end-stage renal disease. J Parenter Enter Nutr 2003;27(1):36-42.

[9] Sridharan S, Wong J, Vilar E, Farrington K. Comparison of energy estimates in chronic kidney disease using doubly-labelled water. J Hum Nutr Diet 2016;29(1):59-66.

[10] Baecke JA, Burema J, Frijters JE. A short questionnaire for the measurement of habitual physical activity in epidemiological studies. Am J Clin Nutr 1982;36(5):936-42.

[11] Heng AE, Montaurier C, Cano N, Caillot N, Blot A, Meunier N, et al. Energy expenditure, spontaneous physical activity and with weight gain in kidney transplant recipients. Clin Nutr 2015;34(3):457-64.

[12] Levey AS, Stevens LA, Schmid CH, Zhang YL, Castro 3rd AF, Feldman HI, et al. A new equation to estimate glomerular filtration rate. Ann Intern Med 2009;150(9):604-12.

[13] Matthews DR, Hosker JP, Rudenski AS, Naylor BA, Treacher DF, Turner RC Homeostasis model assessment: insulin resistance and beta-cell function from fasting plasma glucose and insulin concentrations in man. Diabetologia $1985 ; 28(7): 412-9$.

[14] Matsuda M, DeFronzo RA. Insulin sensitivity indices obtained from oral glucose tolerance testing: comparison with the euglycemic insulin clamp. Diabetes Care 1999;22(9):1462-70.

[15] Weir JB. New methods for calculating metabolic rate with special reference to protein metabolism. J Physiol 1949;109(1-2):1-9.

[16] Montaurier C, Morio B, Bannier S, Derost P, Arnaud P, Brandolini-Bunlon M, et al. Mechanisms of body weight gain in patients with Parkinson's disease after subthalamic stimulation. Brain 2007;130(Pt 7):1808-18.

[17] Ribeyre J, Fellmann N, Montaurier C, Delaitre M, Vernet J, Coudert J, et al. Daily energy expenditure and its main components as measured by whole-body indirect calorimetry in athletic and non-athletic adolescents. Br J Nutr 2000;83(4):355-62.
[18] Twardowski ZJ. PET-a simpler approach for determining prescriptions for adequate dialysis therapy. Adv Perit Dial 1990;6:186-91.

[19] Team RCR. A langage and environment for statistical computing. 2020.

[20] O'Sullivan AJ, Lawson JA, Chan M, Kelly JJ. Body composition and energy metabolism in chronic renal insufficiency. Am J Kidney Dis 2002;39(2):369-75.

[21] Avesani CM, Draibe SA, Kamimura MA, Dalboni MA, Colugnati FA, Cuppari L. Decreased resting energy expenditure in non-dialysed chronic kidney disease patients. Nephrol Dial Transplant 2004;19(12):3091-7.

[22] Kamimura MA, Draibe SA, Avesani CM, Canziani ME, Colugnati FA, Cuppari L. Resting energy expenditure and its determinants in hemodialysis patients. Eur J Clin Nutr 2007;61(3):362-7.

[23] Skouroliakou M, Stathopoulou M, Koulouri A, Giannopoulou I, Stamatiades D, Stathakis C. Determinants of resting energy expenditure in hemodialysis patients, and comparison with healthy subjects. J Ren Nutr 2009;19(4):283-90.

[24] Ikizler TA, Wingard RL, Sun M, Harvell J, Parker RA, Hakim RM. Increased energy expenditure in hemodialysis patients. J Am Soc Nephrol 1996;7(12): 2646-53.

[25] Cuppari L, de Carvalho AB, Avesani CM, Kamimura MA, Dos Santos Lobao RR, Draibe SA. Increased resting energy expenditure in hemodialysis patients with severe hyperparathyroidism. J Am Soc Nephrol 2004;15(11):2933-9.

[26] Avesani CM, Trolonge S, Deleaval P, Baria F, Mafra D, Faxen-Irving G, et al. Physical activity and energy expenditure in haemodialysis patients: an international survey. Nephrol Dial Transplant 2012;27(6):2430-4.

[27] Macdonald JH, Fearn L, Jibani M, Marcora SM. Exertional fatigue in patients with CKD. Am J Kidney Dis 2012;60(6):930-9.

[28] Painter P, Krasnoff JB, Kuskowski M, Frassetto L, Johansen KL. Effects of modality change and transplant on peak oxygen uptake in patients with kidney failure. Am J Kidney Dis 2011;57(1):113-22.

[29] Pajek M, Jerman A, Osredkar J, Ponikvar JB, Pajek J. Association of uremic toxins and inflammatory markers with physical performance in dialysis patients. Toxins (Basel) 2018;10(10).

[30] Thome T, Salyers ZR, Kumar RA, Hahn D, Berru FN, Ferreira LF, et al. Uremic metabolites impair skeletal muscle mitochondrial energetics through disruption of the electron transport system and matrix dehydrogenase activity. Am J Physiol Cell Physiol 2019;317(4):C701-13.

[31] Ikizler TA, Cano NJ, Franch H, Fouque D, Himmelfarb J, Kalantar-Zadeh K, et al. Prevention and treatment of protein energy wasting in chronic kidney disease patients: a consensus statement by the International Society of Renal Nutrition and Metabolism. Kidney Int 2013;84(6):1096-107.

[32] Law S, Davenport A. Glucose absorption from peritoneal dialysate is associated with a gain in fat mass and a reduction in lean body mass in prevalent peritoneal dialysis patients. Br J Nutr 2020:1-8.

[33] Moore MC, Coate KC, Winnick JJ, An Z, Cherrington AD. Regulation of hepatic glucose uptake and storage in vivo. Adv Nutr 2012:3(3):286-94.

[34] Izumida Y, Yahagi N, Takeuchi Y, Nishi M, Shikama A, Takarada A, et al Glycogen shortage during fasting triggers liver-brain-adipose neurocircuitry to facilitate fat utilization. Nat Commun 2013;4:2316.

[35] Lambie M, Chess J, Do JY, Noh H, Lee HB, Kim YL, et al. Peritoneal dialysate glucose load and systemic glucose metabolism in non-diabetics: results from the GLOBAL fluid cohort study. PloS One 2016;11(6):e0155564.

[36] Bernardo AP, Oliveira JC, Santos O, Carvalho MJ, Cabrita A, Rodrigues A. Insulin resistance in nondiabetic peritoneal dialysis patients: associations with body composition, peritoneal transport, and peritoneal glucose absorption. Clin J Am Soc Nephrol 2015;10(12):2205-12. 